Proceedings

\title{
Effects of Caregiver and Gender Differences on Fundamental Motor Skills in 4 - 5 Years Old
}

\author{
Xiaoxia Su ${ }^{1}$ and Qian Chen ${ }^{2, *}$ \\ 1. College of Physical Education and Health Sciences, Zhejiang Normal University, Jinhua 321004, \\ Zhejiang, China; Su091828@zjnu.edu.cn \\ 2. Zhejiang Sports Science Institute, Hangzhou 310004, Zhejiang, China; cq_chenqian@hotmail.com \\ * Correspondence: cq_chenqian@hotmail.com; Tel.: +86-139-0653-6352
}

Publisher's Note: MDPI stays neutral with regard to jurisdictional claims in published maps and institutional affiliations.

Copyright: ( $\odot 2020$ by the authors. Submitted for possible open access publication under the terms and conditions of the Creative Commons Attribution (CC BY) license (http://creativecommons.org/licenses /by/4.0/).

\begin{abstract}
Preschool ages are an important window period for the development of children's fundamental motor skills. Caregiver's behaviour, mannerism, habits and expectations of participating in sports play an important role in the development of children's fundamental motor skills. Grandparents upbringing is a very common phenomenon in China. This study was to compare the preschool children's fundamental motor skills development in China base on different caregivers group and gender. were assessed using the test of gross motor development,third edition (TGMD-3). Two-factor analysis of variance was used to explore the relationship between different genders and different caregivers and children's fundamental motor skills. The interaction between the total score of object control and the development of ball catching was significant $(\mathrm{P}<0.05)$. On the premise of different genders, there was a difference between the Parent care group and the eldercare group in different caregiver groups, and performing boys in the parent care group was better than that of the eldercare group $(\mathrm{P}<0.05)$. No such difference was seen among girls; On the premise of different caregivers, there were differences between the two genders in the parent care group, and boys performed better than girls $(\mathrm{P}<0.05)$. No such difference was observed in the elder care group. There are differences in the development of object control skills among different caregivers and children aged 4-5 years of age with different genders, so the training of object control motor skills among different caregivers should be strengthened to avoid the difference in basic motor development of children caused by the difference between caregivers and gender.
\end{abstract}

Keywords: Children;Caregivers;Sex;Fundamental motor skills

\section{Introduction}

The development of Fundamental Motor Skills (FMS) is a stage in early childhood, and FMS is usually classified as Locomotor Skills, such as （running, jumping, etc）. and Object Control Skills, such as (catching and throwing) [1].The development of FMS in children lays the foundation for many of the professional motor skills they will need for successful participation in sports and physical activity [2].The Guide to Learning and Development for 3-6 year olds clearly sets "motor development" as the goal of children's learning and development.Children basic sports skill level can be made to improve their physique level can be improved greatly [3,4]. children early to participate in sports activities is to maintain healthy adulthood catalyst, the development of basic sports skills not only affect children's adult physique level, more and cardiovascular disease, chronic non-communicable diseases such as cancer and diabetes are closely related.According to psychological research, in a certain age period, individuals are very sensitive to certain knowledge or behavior, so it is very easy to learn. If you miss this period, it will be more difficult to learn later ${ }^{[5]}$.Before the age of about 12 , children tend to imitate the actions 
and behaviors of the primary caregivers (such as parents and grandparents), so as to improve their athletic ability. When the primary caregivers show recognition of children's abilities in some aspects, it will increase children's recognition of their own abilities and make children more willing to make efforts ${ }^{[6]}$.Therefore, the main caregivers need to pay more attention to the development of children's fundamental motor skills, provide opportunities for children's physical activities, so as to develop children's fundamental motor skills to a skilled level, and lay a solid foundation for improving children's physical health.

A survey on the "Grandparents upbringing" in China shows that among 0-6 year old children in Shanghai, 50\%-60\% are mainly nursed by the elderly, and the nurse-oriented children in Guangzhou account for about $50 \%$ of the total, while in Beijing the proportion is as high as $70 \%$. Moreover, the younger the child is, the higher the proportion is with the elder nurse-oriented children [7].The role of grandparents in family care of grandchildren and their impact on children's health and development have received more systematic attention ${ }^{[8] . S a d r u d d i n d ~ e t ~ a l . ~}{ }^{[9]}$ pointed out that grandparent care has an important impact on children's health and development.

Sandra et al. ${ }^{[10]}$ showed that if caregivers can actively interact with children, it will have a positive impact on the development of children's sports ability.Studies have shown that the absence of parental roles can put children at a disadvantage and prevent them from realizing their full development potential [11].Studies have confirmed that there are differences in the development of fundamental motor skills of preschoolers between different genders ${ }^{[12-15]}$. Meanwhile, family environment ${ }^{[16]}$ (such as caregivers, economic income, etc.) also has an impact on the development of fundamental motor skills of preschoolers. Although these studies have discussed the influence of fundamental motor skills of preschoolers from multiple levels, they have not analyzed the interaction between different levels. Preschoolers have a preliminary understanding of social environment, and observation and imitation are the main ways to express behaviors at this stage.The behavior, mannerisms, habits and expectations of the caregiver to participate in sports play an important role in the development of their fundamental motor skills. The purpose of this paper is to study preschool children on the basis of fundamental motor skills development, to explore different caregivers groups with different gender on 4 to 5 years old school the day before yesterday the effect of fundamental motor skills development, improve the caregivers action of different gender children's cognitive development, thus to improve children's ability to provide theoretical basis for the overall basic motion.

\section{Methods}

\subsection{Participants}

Using cluster sampling, 751 children aged 4-5 years from 6 kindergartens in Zhejiang province, China were selected to take part in the study. According to the research plan, the kindergarten teachers and the caregivers of the test subjects were interviewed and their consent was got before the test. The selected subjects' motor abilities were at the normal development level of their peers, and the specific screening criteria were: 1) No major physical diseases, no physical deformity; 2) Normal physical development can take part in sports; 3) No intellectual or mental disorder; 4) No genetic history. During the test, 23 subjects dropped out for their own reasons, and 728 valid experimental samples were kept at last. The basic information of the subjects is shown in Table 1. There are no significant differences in height, weight and body mass index (BMI) between male and female in different care groups. 
Table 1. Basic information of subjects.

\begin{tabular}{cccccc}
\hline Caregiver & gender & $\mathbf{n}$ & height/cm & weight/kg & BMI \\
\hline \multirow{2}{*}{ Parent care group } & boy & 213 & $111.726 \pm 6.932$ & $20.155 \pm 8.761$ & $16.472 \pm 7.518$ \\
& girl & 229 & $112.686 \pm 6.813$ & $20.387 \pm 7.489$ & $16.012 \pm 3.245$ \\
\multirow{2}{*}{ Elder care group } & boy & 141 & $113.631 \pm 5.634$ & $21.471 \pm 6.560$ & $16.218 \pm 6.56$ \\
& girl & 145 & $114.015 \pm 6.771$ & $21.218 \pm 6.719$ & $16.149 \pm 4.257$ \\
\hline
\end{tabular}

\subsection{Scoring protocol}

In this study, a strict testing procedure was adopted. Two professionally trained testers tested the subjects and scored the children's gross motor development level according to the scale scoring criteria. Each test was conducted by the same group of testers. Before the experiment, all participants watched a training video on the University of Michigan's TGMD-3 website and took part in an offline training session. Before the test, according to the TGMD-3 test manual, a tester will give a verbal description and accurate demonstration for the children. During the test, the tester will first show the movement correctly once, and let the subjects observe and let the subjects watch it. Then the subjects will complete the test independently according to the movements of the experimenter and then conduct the second test. If the subject did not understand or perform the test correctly, the same tester provided additional demonstrations, and all the actions were measured twice in a row. Each skill is tested on three to five motor skill criteria. For example, the "forward slide" is tested by bending the arms and swinging forward. When this action occurs during the evaluation, record "1", and if not completed, record " 0 ".

\section{Results}

Displacement class action skills and basic movement overall scores between different gender caregivers group there is no significant difference $(p>0.05)$, the control object class action skills development exist significant differences between different gender caregivers group $(\mathrm{p}<0.05)$, and there is interaction, effect size between the main body to carry on the simple effect analysis: on the premise of different gender and different caregivers group parents care there are differences between the group and elder care, and the boy's parents care group performance is superior to the old man care to give priority to group ( $p<0.05)$, not appear this difference in girls; On the premise of different caregivers, there was a difference between the two genders in the parental care-giving group, and boys performed better than girls $(\mathrm{P}<0.05)$. No such difference was found in boys (see Table 2).

Table 2. Differences in fundamental motor skills of 4-5 year-old children between different genders and different caregiver group.

\begin{tabular}{|c|c|c|c|c|c|c|c|}
\hline \multirow{2}{*}{$\begin{array}{l}\text { Relevant } \\
\text { indicators }\end{array}$} & \multicolumn{2}{|c|}{ Parent care group $(\mathrm{N}=442)$} & \multicolumn{2}{|c|}{ Elder care group $(\mathrm{N}=286)$} & \multirow{2}{*}{ Fgender } & \multirow{2}{*}{$\begin{array}{l}\text { FCare- } \\
\text { giver }\end{array}$} & \multirow{2}{*}{$\begin{array}{c}\mathrm{F}_{\text {gender }}{ }^{*} \mathrm{Car} \\
\text { egiver }\end{array}$} \\
\hline & Boy & girl & Boy & girl & & & \\
\hline $\begin{array}{c}\text { (Locomotor } \\
\text { Skill }\end{array}$ & $27.384 \pm 7.762$ & $26.225 \pm 8.441$ & $25.216 \pm 8.489$ & $27.742 \pm 7.823$ & 1.313 & 0.256 & $8.227^{*}$ \\
\hline $\begin{array}{l}\text { Object Con- } \\
\text { trol Skill }\end{array}$ & $24.665 \pm 8.442$ & $21.195 \pm 7.302$ & $21.955 \pm 7.493$ & $21.379 \pm 7.034$ & $10.952^{* *}$ & $4.269^{*}$ & $5.064^{*}$ \\
\hline Total & $\begin{array}{c}52.049 \pm 14.64 \\
5\end{array}$ & $47.420 \pm 14.123$ & $47.171 \pm 14.486$ & $49.121 \pm 13.473$ & 1.406 & 1.976 & $8.476^{* *}$ \\
\hline
\end{tabular}


Through the two-factor variance analysis of the relationship between different genders and different caregivers and the fundamental motor skills of 4-5 years old children, the results showed that there was no significant difference in the development of fundamental motor skills in running, front sliding step, side sliding step, front spanking jump, standing long jump, and one-legged jump ( $p>0.05)$ (see table 3$)$.

Table 3. Differences in displacement motor skills of 4-5 year-old children in different genders and caregiver groups.

\begin{tabular}{|c|c|c|c|c|c|c|c|}
\hline \multirow{2}{*}{ Relevant indicators } & \multicolumn{2}{|c|}{ Parent care group $(\mathrm{N}=442)$} & \multicolumn{2}{|c|}{ Elder care group $(\mathrm{N}=286)$} & \multirow{2}{*}{ Fgender } & \multirow{2}{*}{ FCaregiver } & \multirow{2}{*}{$\begin{array}{c}\text { Fgender*Caregiv }^{*} \\
\text { er }\end{array}$} \\
\hline & boy & gril & boy & gril & & & \\
\hline Run & $6.247 \pm 1.369$ & $5.788 \pm 1.437$ & $5.964 \pm 1.489$ & $5.976 \pm 1.259$ & 4.107 & 0.187 & 4.554 \\
\hline Gallop & $5.125 \pm 1.819$ & $4.831 \pm 1.807$ & $4.901 \pm 1.716$ & $5.250 \pm 1.819$ & 0.036 & 0.467 & 5.098 \\
\hline Hop & $4.266 \pm 2.011$ & $4.081 \pm 2.147$ & $3.820 \pm 2.201$ & $4.516 \pm 2.014$ & 2.385 & 0.001 & 7.114 \\
\hline Skip & $3.460 \pm 1.883$ & $3.589 \pm 2.039$ & $3.198 \pm 1.999$ & $3.815 \pm 1.948$ & 5.739 & 0.014 & 2.445 \\
\hline Slide & $3.589 \pm 1.687$ & $3.436 \pm 1.909$ & $3.144 \pm 2.008$ & $3.540 \pm 1.876$ & 0.694 & 1.367 & 3.537 \\
\hline $\mathrm{HJ}$ & $4.696 \pm 2.003$ & $4.500 \pm 2.084$ & $4.189 \pm 2.278$ & $4.645 \pm 2.021$ & 0.625 & 1.207 & 3.925 \\
\hline
\end{tabular}

Note: ${ }^{*}$ means $\mathrm{P}<0.05,{ }^{* *}$ means $\mathrm{P}<0.01$.

By two-factor variance analysis, the relationship between the fundamental motor skills of Boys performs better than girls in the development of object manipulation motor skills. Pitch in laid hands on him, catching, kick the ball in the fixed categories don't exist in the difference between the different care parents care give priority to group performance is superior to the old man care is given priority to, significant interactions in the ball movement, effect measure to carry on the simple effect between the main body analysis: on the premise of different gender and different caregivers group parents care there are differences between the group and elder care, and the boy's parents care group performance is superior to the old man care to give priority to group $(p<0.05)$, did not appear in the girl's parents care to give priority to group performance is superior to the old man care to give priority to group the difference; On the premise of different caregivers, there were differences between the two genders in the parental care group, and boys performed better than girls $(\mathrm{P}<0.05)$. No such difference was found between boys and girls in the elder care group (see Table 4).

Table 4. Differences in object manipulation motor skills of 4-5 year-old children in different genders and caregiver groups.

\begin{tabular}{|c|c|c|c|c|c|c|c|}
\hline \multirow{2}{*}{ Relevant indicators } & \multicolumn{2}{|c|}{ Parent care group $(\mathrm{N}=442)$} & \multicolumn{2}{|c|}{ Elder care group $(\mathrm{N}=286)$} & \multirow{2}{*}{$F_{\text {gender }}$} & \multirow{2}{*}{ FCaregiver } & \multirow{2}{*}{$\begin{array}{c}\text { Fender*Caregi } \\
\text { ver }\end{array}$} \\
\hline & boy & gril & boy & gril & & & \\
\hline OH Throw & $4.403 \pm 2.005$ & $4.119 \pm 1.866$ & $4.126 \pm 2.068$ & $4.177 \pm 1.852$ & 0.571 & 0.500 & 1.185 \\
\hline UH Throw & $3.593 \pm 2.067$ & $2.822 \pm 1.736$ & $3.027 \pm 1.637$ & $2.508 \pm 1.655$ & $19.667^{* *}$ & $9.153^{*}$ & 0.751 \\
\hline Catch & $2.848 \pm 1.820$ & $2.360 \pm 1.471$ & $2.351 \pm 1.444$ & $2.323 \pm 1.506$ & 4.137 & $4.424^{*}$ & $3.266^{*}$ \\
\hline Dribble & $3.418 \pm 1.536$ & $3.254 \pm 1.489$ & $2.982 \pm 1.471$ & $3.516 \pm 1.445$ & 2.438 & 0.541 & $8.673^{*}$ \\
\hline FH Strike & $2.810 \pm 1.667$ & $2.436 \pm 1.619$ & $2.378 \pm 1.532$ & $2.597 \pm 1.508$ & 0.371 & 1.135 & $5.409^{*}$ \\
\hline T-H Strike & $2.707 \pm 1.710$ & $2.013 \pm 1.357$ & $2.676 \pm 1.690$ & $2.177 \pm 1.758$ & $21.837^{* *}$ & 0.272 & 0.059 \\
\hline T-H Catch & $4.886 \pm 1.614$ & $4.191 \pm 1.561$ & $4.414 \pm 1.626$ & $4.081 \pm 1.591$ & $16.574^{* *}$ & $5.294^{* *}$ & 2.045 \\
\hline
\end{tabular}

\section{Discussion}

This study found that only the catch item had significant interaction among object control items.. Studies have shown that children's ability was positively related to the intensity of moderate physical activity over the weekend, and have nothing to do with a working day of physical activity, different basic sports skills and physical activity at different times of the strength there is a certain correlation, compared to girls, boys more 
moderate physical activity intensity over the weekend, the boy's object control [17] skill score significantly higher than the girls. In addition, studies have found that the combination skills of catching the ball are positively correlated with the intensity of moderate and low physical activity [18]. In this study, it is found that children at this age spend most of their weeks in the kindergarten and spend most of their weekends with their parents. Studies have shown that parents have more time and opportunities to interact with children on weekends [19], and among all object control skills, the interaction required for ball catching is the highest, which may be one reason the parent care-giving group of ball catching is higher than the elder care-giving group. In addition, weekend parents can directly (such as providing equipment, outdoor activities) and indirect (e.g., characters, encourage) influence the development of the basic sports skills of children [20], grandparents compared with parents, grandparents and older body activity is relatively poor, it may inadvertently make the child lost many opportunities for development of basic sports skills. The influence of gender roles prompts boys to take part more in object control projects, and boys will have more interaction with their parents in the ball catching project, thus leading to better performance of boys in the parent care group than girls, and boys in the parent care group than boys in the elder care group.

\section{Conclusion}

In terms of the overall score of object control motor skills and ball catching, performing boys in the parent nursing group was better than that in the elderly nursing group $(\mathrm{P}<0.05)$, but no such difference was found in girls. Boys performed better than girls in the parent care group $(\mathrm{P}<0.05)$, but no such difference was found in the elder care group.

Funding: This study was funded by the Zhejiang Provincial Welfare Technology Application Research Project of China, grant number 2017C3076.

Acknowledgments: Thanks to 7 kindergartens in Hangzhou for participation in this intervention.

Conflicts of Interest: No conflict of interest was declared.

\section{Reference}

1. HAYWOOD K M, GETCHELL N., 2009. Lifespan motor development. In: Human Kinetics,Champaign, IL, USA, 5th ed.

2. KELLY L, CONNOR S O, HARRISON A J, et al. Does fundamental movement skill proficiency vary by sex, class group or weight status? Evidence from an Irish primary school setting[J]. Journal of Sports Sciences. 2019, 37(9): 1055-1063.

3. FIGUEROA R, AN R. Motor Skill Competence and Physical Activity in Preschoolers: A Review.[J]. Maternal and child health journal. 2017, 21(1).

4. Hu Shuiqing, Wang Huan, Li Yichen. The relationship between the national physical fitness test scores and the development of gross motor skills of children aged 3-6 years in Beijing [J].China Sports Science and Technology. 2018, 54(5): 32-37.

5. Dong Qi, Tao Sha. Action and psychological development [M]. Beijing Normal University Press, 2004:243.

6. SILVA M J C E, FIGUEIREDO A J, ELFERINK-GEMSER M T, et al. Parental influences on youth sport participation[J]. Youth Sports: participation, trainability and readiness. 2009: 75-102.

7. Chen Lu, ZHANG Yue-fei, Chen Chuanfeng. Advantages and Disadvantages of Inter-generational parenting: An Overview of research on the influence of Grandparents, Parents and Grandchildren [J].Early Childhood Education. 2014(12): 52-56.

8. Liu Dongning, Lu Liping, ZHANG Ying, et al. Influence of part of modern lifestyle on physical health of kindergarten children aged $3 \sim 6$ years in Shanghai [J].Chinese Journal of Child Health. 2016, 24(4): 413-416. 
9. SADRUDDIN A F A, PONGUTA L A, ZONDERMAN A L, et al. How do grandparents influence child health and development? A systematic review[J]. Social Science \& Medicine. 2019, 239.

10. SANDRA B, MICHAEL L L, JONATHAN C M. Parenting Behaviors in the First Year of Life: A National Comparison of Latinos and Other Cultural Communities[J]. Journal of Latinos and Education. 2007, 6(3).

11. Gao Yajing, ZHAO Chunxia, ZHANG Jingxu, et al. Influence of parents' migrant work on the early development of left-behind children aged $0 \sim 3$ years [J].Chinese Journal of Reproductive Health. 2018, 29(4): 301-306.

12. AYE T, KURAMOTO-AHUJA T, SATO T, et al. Gross motor skill development of kindergarten children in Japan.[J]. Journal of physical therapy science. 2018, 30(5).

13. GUO H, SCHENKELBERG M A, O'NEILL J R, et al. How Does the Relationship Between Motor Skill Performance and Body Mass Index Impact Physical Activity in Preschool Children?[J]. Pediatr Exerc Sci. 2018, 30(2): 266-272.

14. GUI Chunyan, WANG Ronghui, LIU Xin. Research progress on the Correlation between basic motor skills and physical activity in children [J].Journal of Physical Education. 2019, 26(2): 89-95.

15. Ning Ke, Shen Xinsheng, SHAO Xiaojun. Empirical Study on the Relationship between the development of mobile Movement and perceived physical ability in children aged $3 \sim 6$ years [J].Journal of Beijing Sport University. 2016, 39(12): 74-81.

16. Lv Hailong, WANG Kaizhen, LIU Hong. Family Sports Environment and Children's Sports Lifestyle: Mediating Role of Family Social Capital [J].Journal of Beijing Sport University. 2020, 43(5): 77-88.

17. LAWRENCE F, ZOE K, NICOLA D R, et al. Fundamental movement skills in relation to weekday and weekend physical activity in preschool children[J]. Journal of Science and Medicine in Sport. 2015, 18(6).

18. LIVONEN K S A, SÄÄKSLAHTI A K A, MEHTÄLÄ A B, et al. Relationship between fundamental motor skills and physical activity in 4-year-old preschool children(Article)[J]. Perceptual and Motor Skills. 2013(2): 627-646.

19. O'DWYER M A, FAIRCLOUGH S J A, RIDGERS N D B, et al. Patterns of objectively measured moderate-To-vigorous physical activity in preschool children(Article)[J]. Journal of Physical Activity and Health. 2014(6): 1233-1238.

20. HINKLEY T, SALMON J, OKELY A, et al. Multidimensional correlates of preschool children's physical activity[J]. Journal of Science and Medicine in Sport. 2012: S110-S111. 